\title{
Chemiluminescence of Acanthamoeba castellanii
}

\author{
By David LLOYD,* Alberto BOVERIS, $\uparrow$ Rudolf REITER, Mark FILIPKOWSKI and Britton CHANCE \\ Johnson Research Foundation, School of Medicine, University of Pennsylvania, Philadelphia, PA 19174, U.S.A.
}

\section{(Received 20 February 1979)}

\begin{abstract}
1. Chemiluminescence of Acanthamoeba castellanii in the presence of $\mathrm{O}_{2}$ was of similar intensity in organisms harvested early or late during exponential growth [when cyanide $(1 \mathrm{mM}$ ) stimulates or inhibits respiration respectively]. 2. Cyanide (up to $1.5 \mathrm{~mm}$ ) stimulated photoemission in both types of organism by $250-300$ photons/s per $10^{7}$ cells above the value observed under aerobic conditions. 3. 'Dibromothymoquinone' (2,5-dibromo-6isopropyl-3-methyl-p-benzoquinone) (up to $80 \mu \mathrm{M}$ ) further increased chemiluminescence. 4. Similar responses were also demonstrated in whole homogenates and in subcellular fractions; $36 \%$ of the chemiluminescence was provided by a fraction sedimenting at $100000 \mathrm{~g}$-min, and $20 \%$ in that fraction that was non-sedimentable at $200000 \mathrm{~g}$-min. 5. Mitochondrial substrates (succinate, 2-oxoglutarate, NADH) in the presence or absence of ADP and $P_{i}$ or peroxisomal substrates (glycollate, urate or ethanol) gave no increases in light emission by whole homogenates or in any of the fractions. 6 . It is suggested that reactions responsible for production of chemiluminescence are those primarily producing superoxide anions and leading to lipid peroxidation and singlet-oxygen formation. Photoemission enhancement and superoxide dismutase inhibition showed similar cyanide concentration-dependencies.
\end{abstract}

A weak ('low-level') chemiluminescence has been detected from mouse liver, muscle and brain (Tarusov et al., 1961, 1962), and in yeast (Stauff \& Reske, 1964; Esser \& Stauff, 1968; Quickenden \& QueHee, 1974). Studies with rat liver microsomal fractions suggested that reactions responsible for this chemiluminescence include oxidative chain reactions producing singlet oxygen, hydroxy radicals and lipoperoxides (Pyatenko \& Tarusov, 1964; Howes \& Steele, 1971, 1972; Nakano et al., 1976; Sugioka \& Nakano, 1975). Rat liver mitochondria also produce a weak chemiluminescence (Boveris et al., 1979). Intermediary stages in the reduction of molecular oxygen, for instance in the ubiquinone-cytochrome $b$ region of the respiratory chain, yield superoxide anions and hence hydrogen peroxide by way of superoxide dismutase (Loschen et al., 1971; Boveris et al., 1972; Loschen et al., 1974; Boveris \& Cadenas, 1975), probably at the redox level of ubisemiquinone (Boveris et al., 1976; Cadenas et al., 1977). Superoxide generation in plant mitochondria also occurs at the flavoprotein region of the NADH dehydrogenase segment of the respiratory chain (Rich \& Bonner, 1978). The primary generation of super-

* Permanent address: Department of Microbiology, University College, Newport Road, Cardiff CF2 1TA, Wales, U.K.

† Permanent address: Instituto de Quimica Biologica, Paraguay 2155, Universidad de Buenos Aires, 1121 Buenos Aires, Argentina. oxide anions and hydrogen peroxide may thus be linked to chain reactions leading to lipid peroxidation (Chance \& Boveris, 1978) and to the production of chemiluminescent species in a number of membrane redox systems.

The soil amoeba Acanthamoeba castellanii has a branched mitochondrial electron-transport chain, terminating in three distinct oxidases (Edwards et al., 1977; Edwards \& Lloyd, 1977, 1978a,b). The main respiratory chain terminates in cytochrome $a+a_{3}$, which is azide- and cyanide-sensitive. A second oxidase is azide- and cyanide-insensitive but is inhibited by salicylhydroxamic acid. The third oxidase is insensitive to azide and salicylhydroxamic acid but is inhibited by cyanide. Dibromothymoquinone, acting as an analogue of ubiquinone, inhibits mitochondrial electron transport at the ubiquinone-cytochrome $b$ region of the respiratory chain (Trebst et al., 1970); in A. castellanii this compound decreases electron flux through both the azide- and salicylhydroxamic acid-sensitive pathways but not that through the third oxidase (S. W. Edwards $\&$ D. Lloyd, unpublished work). The relative electron flux through these oxidases changes as organisms grow in a batch culture; organisms harvested in early phase of exponential growth show cyanidestimulated respiration, and in these organisms respiration can proceed by way of two pathways alternative to the main phosphorylating chain (Lloyd et al., 1979). In late-exponential-phase 
cultures the pathway of electron transport is to a greater extent by way of a conventional cyanide- and azide-sensitive cytochrome $c$ oxidase having a high affinity for oxygen.

In the present paper we report that the intensity of photon emission in $A$. castellanii is similar both in organisms with cyanide-stimulated and with cyanideinhibited respiration; chemiluminescence is observed in four subcellular fractions and is enhanced by cyanide alone or by cyanide plus dibromothymoquinone.

\section{Experimental}

\section{Maintenance and growth of the organism}

Acanthamoeba castellanii was maintained and grown axenically with shaking at $30^{\circ} \mathrm{C}$ exactly as described previously (Edwards et al., 1977). Organisms were counted in a Fuchs-Rosenthal haemocytometer slide (Baird and Tatlock, Chadwell Heath, Romford, Essex, U.K.) after suitable dilution with $50 \mathrm{~mm}-\mathrm{MgCl}_{2}$.
Harvesting of cultures, cell disruption and subcellular fractionation

Cultures were harvested by centrifugation at $100 \mathrm{~g}$ for $1.5 \mathrm{~min}$ in the $6 \times 250 \mathrm{ml}$ rotor of a Sorvall RB2 centrifuge. Organisms were washed twice in $50 \mathrm{mM}-\mathrm{MgCl}_{2}, \mathrm{pH} 6.0$, and resedimented. Resuspension in $3 \mathrm{vol}$. of $50 \mathrm{~mm}-\mathrm{MgCl}_{2}$ provided the cell suspensions for experiments with non-proliferating whole cells. For subcellular fractionation, the organisms were resuspended in $0.32 \mathrm{M}$-sucrose $/ 10 \mathrm{~mm}$ Tris/ $\mathrm{H}_{2} \mathrm{SO}_{4} / 0.2 \mathrm{~mm}$-EGTA, pH8.0. Disruption was by hand in a glass homogenizer with Teflon pestle (A. H. Thomas, P.O. Box 779, Philadelphia, PA, U.S.A.); six strokes were adequate for about $90 \%$ cell breakage. Remaining whole cells together with nuclei were removed by centrifugation at $1000 \mathrm{~g}$ $\left(r_{\text {av }} .7 .5 \mathrm{~cm}\right)$ for $8 \mathrm{~min}$ in the $8 \times 50 \mathrm{ml}$ rotor of the Sorvall RB2 centrifuge. The supernatant ('cell-free extract') was carefully removed and centrifuged at $10000 \mathrm{~g}\left(r_{\mathrm{av}} .7 .6 \mathrm{~cm}\right)$ for $10 \mathrm{~min}$. The sediment was resuspended in $5 \mathrm{vol}$. of the disruption buffer and resedimented at $10000 \mathrm{~g}\left(r_{\mathrm{av}} .7 .6 \mathrm{~cm}\right)$ for $10 \mathrm{~min}$ to

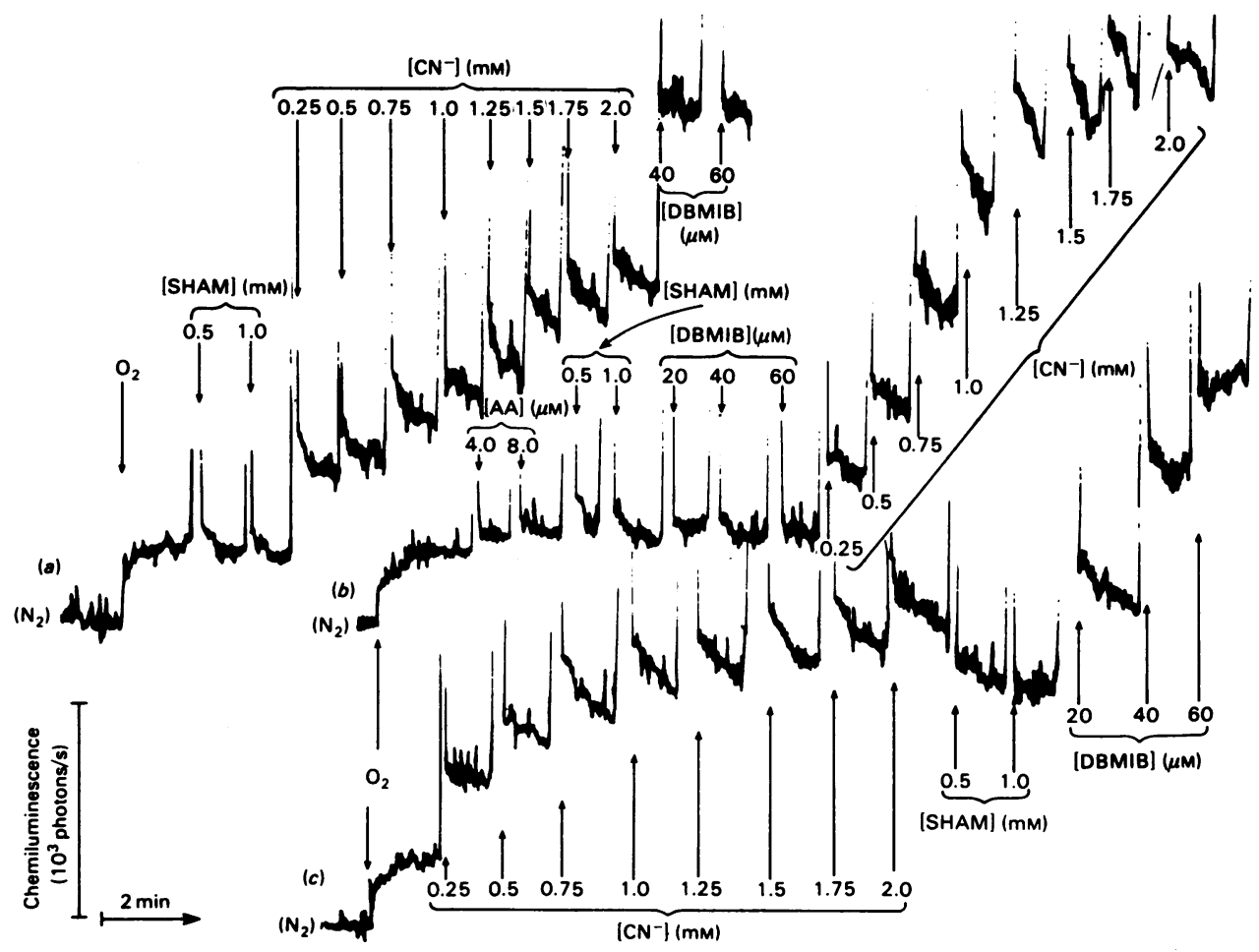

Fig. 1. Chemiluminescence of intact-cell suspensions of early-exponential-phase A. castellanii

Organisms were harvested at a cell density of $3.1 \times 10^{5}$ cells $/ \mathrm{ml}$ and resuspended at $4.4 \times 10^{7}$ cells $/ \mathrm{ml} \mathrm{in} 50 \mathrm{~mm}-\mathrm{MgCl}_{2}$. Abbreviations used: SHAM, salicylhydroxamic acid; DBMIB, dibromothymoquinone; AA, antimycin A. (a), (b) and (c) represent three traces of chemiluminescence. 
give a pellet $\left(P_{1}\right)$ and supernatant $\left(S_{1}\right)$; the postmitochondrial supernatant was centrifuged at $20000 \mathrm{~g}$ for $10 \mathrm{~min}$ to yield a pellet $\left(\mathrm{P}_{2}\right)$ and a final supernatant $\left(\mathbf{S}_{2}\right)$. $\mathbf{P}_{2}$ was resuspended in $5 \mathrm{vol}$. of disruption buffer.

\section{Measurement of chemiluminescence}

The single-photon counting utilized a $5 \mathrm{~cm}$-endwindow photomultiplier (8850, RCA Electronic Components, Harrison, NY 07029, U.S.A.) responsive in the spectral range $300-650 \mathrm{~nm}$, with an applied voltage of $1.8 \mathrm{kV}$, connected to an amplifier-discriminator (Princeton Applied Research, P.O. Box 2565, Princeton, NY 08540, U.S.A.) adjusted for single photons. The output was monitored with a frequency counter (Heath IB1110, Heath Co., Benton Harbor, MI 49022, U.S.A.) and a potentiometric recorder. The photomultiplier was sealed into an Ortec housing and surrounded by solid $\mathrm{CO}_{2}$; the tube temperature was approx. $-30^{\circ} \mathrm{C}$. A Lucite (Perspex) rod $(22 \mathrm{~cm}$ long, $5 \mathrm{~cm}$ diam.) enclosed in aluminium foil served as optical coupler and also ensured thermal isolation from the sample. Suspensions $(4.5 \mathrm{ml})$ were held in a Lucite cuvette $\left(35 \mathrm{~mm} \times 35 \mathrm{~mm} \times 5 \mathrm{~mm}, 12.25 \mathrm{~cm}^{2}\right.$ surface area) placed in front of the optical coupler and maintained at $30^{\circ} \mathrm{C}$. Gassing of the cuvette contents was via two stainless-steel microtubes (gauge no. 24) placed at the bottom corners of the cuvette. A plan of the apparatus has been published elsewhere (Boveris et al., 1979).

\section{Other analytical procedures}

Dissolved oxygen concentrations were measured simultaneously with chemiluminescence by using a Teflon-covered Clark electrode in a specially designed cuvette (total vol. $9 \mathrm{ml}$ ). Cytochrome $c$ oxidase (EC 1.9.3.1) activity was measured by the method of Smith (1955), catalase (EC 1.11.1.6) was determined as described by Lück (1963), and superoxide dismutase (EC 1.15.1.1) as described by Boveris \& Stoppani (1977). Protein was assayed by the pro-

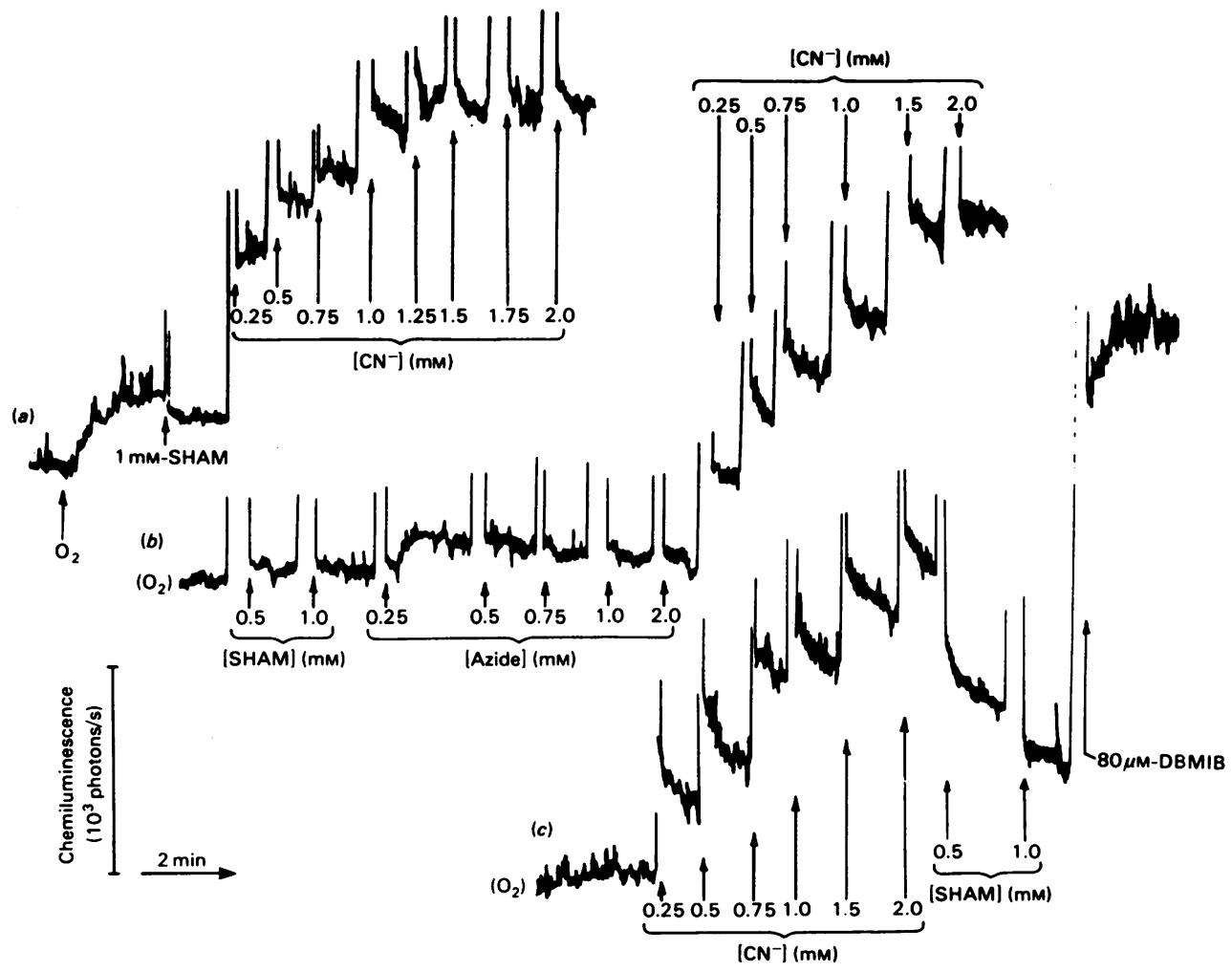

Fig. 2. Chemiluminescence of intact-cell suspensions of late-exponential-phase A. castellanii

Organisms were harvested at a cell density of $1.7 \times 10^{6}$ cells $/ \mathrm{ml}$ and resuspended to $4 \times 10^{7}$ cells $/ \mathrm{ml} \mathrm{in} 50 \mathrm{mM}-\mathrm{MgCl}_{2}$. Abbreviations used: SHAM, salicylhydroxamic acid; DBMIB, dibromothymoquinone. $(a),(b)$ and $(c)$ represent three traces of chemiluminescence.

Vol. 184 
cedure of Lowry et al. (1951), with bovine serum albumin as standard.

\section{Chemicals}

Cytochrome $c$ (type III, from horse heart) NADH (type III, from yeast), ATP, ADP, xanthine oxidase, adrenaline (epinephrine), antimycin A, sodium glycollate and sodium urate were all from Sigma. t-Butyl hydroperoxide and dimethylfuran were from Aldrich Chemical Co., Milwaukee, WI, U.S.A. Bovine serum albumin was from Armour Pharmaceutical Co., Eastbourne, Sussex, U.K. 'Dibromothymoquinone' (2,5-dibromo-6-isopropyl-3-methylp-benzoquinone) was from Dr. W. Draber, Bayer A.G. BRD 56 Wuppertal, Germany.

\section{Results}

\section{Chemiluminescence of whole-cell suspensions}

Light emission by organisms from an earlyexponential-phase culture is shown in Fig. 1. An anaerobic suspension of organisms gave a count of 1100 photons/s. Oxygenation increased the intensity of chemiluminescence by 500 photon/s. Salicylhydroxamic acid ( $1 \mathrm{~mm})$ gave no response, but sequential additions of cyanide $(0.25-2 \mathrm{~mm}$ in eight equal steps) produced a considerable enhancement of light-emission (Fig. 1a). A further increase in light-intensity was seen on adding $40 \mu \mathrm{M}$-dibromothymoquinone. Antimycin A (up to $8 \mu \mathrm{M}$ ) produced no significant increase in chemiluminescence (Fig. $1 b)$, neither did subsequent additions of $1 \mathrm{~mm}$ salicylhydroxamic acid and dibromothymoquinone $(60 \mu \mathrm{M})$. Cyanide (up to $2 \mathrm{~mm}$ ) increased chemiluminescence when added last in this sequence. Fig. 1(c) shows that cyanide alone also increased the response; salicylhydroxamic acid added after cyanide gave no effect. The declining signals in the presence of cyanide were due to loss of the inhibitor from the oxygenated system at the $\mathrm{pH}$ used (pH6.0). Dibromothymoquinone (up to $60 \mu \mathrm{M}$ ) added after cyanide and salicylhydroxamic acid again gave elevated responses. Quenching of the chemiluminescence (results not shown) occurred on adding $15 \mathrm{~mm}$-dimethylfuran.

As the response to inhibitors of respiration of organisms from the early- and late-exponential

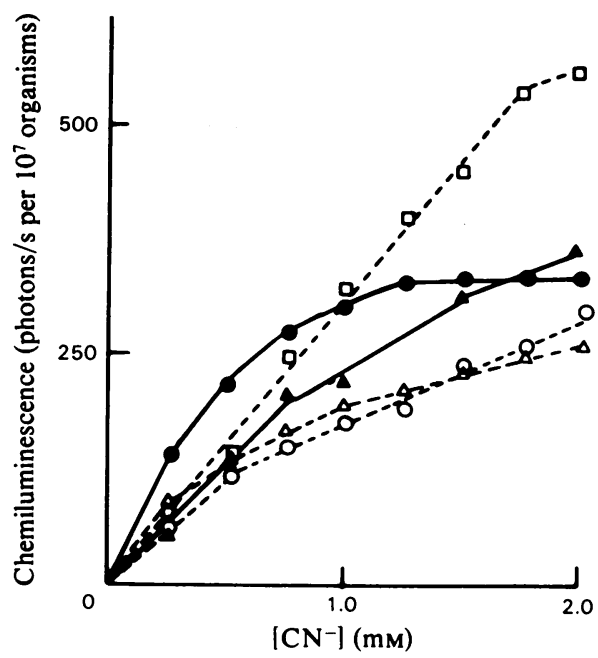

Fig. 3. Effects of respiratory inhibitors on the intensity of photon emission by whole-cell suspensions of $A$. castellanii Open symbols, early-exponential-phase organisms; closed symbols, late-exponential-phase organisms. $\mathbf{\Delta}$, $\triangle$, Cyanide alone; $\bullet, 0$, salicylhydroxamic acid ( $1 \mathrm{~mm})$ added before cyanide; $\square$, salicylhydroxamic acid $(1 \mathrm{mM})$ and dibromothymoquinone $(60 \mu \mathrm{M})$ added before cyanide. The zero value on the ordinate represents photon emission in the oxygenated suspensions.

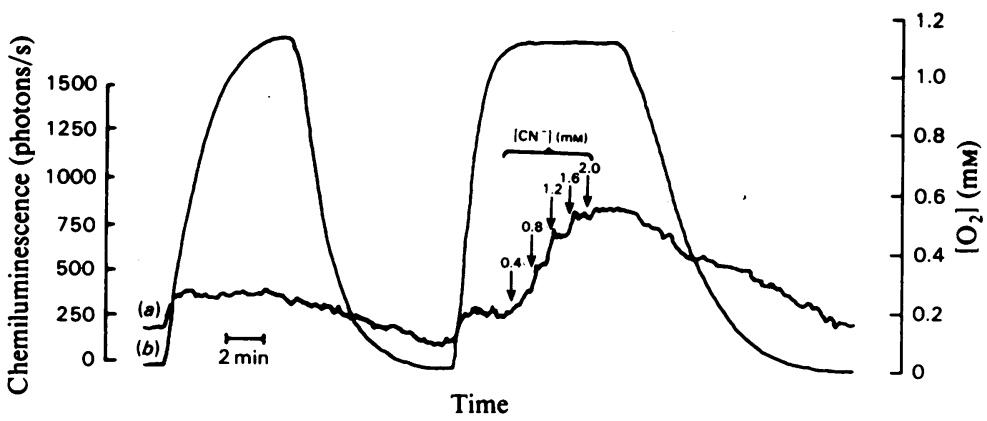

Fig. 4. Chemiluminescence of whole-cell suspension of $A$. castellanii: responses to oxygenation and anaerobiosis Organisms were harvested in late-exponential phase of growth and resuspended in $50 \mathrm{~mm}-\mathrm{MgCl}_{\mathbf{2}}(\mathrm{pH} 6.0)$ at $3.1 \mathrm{mg}$ of protein $/ \mathrm{ml}$. Additions of cyanide were made where indicated by the arrows. $(a)$, Chemiluminescence; $(b),\left[\mathrm{O}_{2}\right]$. 
phases of growth are quite different (see the introduction), a similar experiment was performed with organisms harvested at a later stage in growth. Fig. 2 shows that cyanide in the presence (Fig. $2 a$ ) or absence (Fig. 2c) of salicylhydroxamic acid produced a similar elevation of emitted light-intensities. Azide (up to $2 \mathrm{~mm}$ ) gave no response in the presence of salicylhydroxamic acid, and dibromothymoquinone $(80 \mu \mathrm{M})$ added after cyanide gave a large response. The final intensities of emission from organisms in the presence of $2 \mathrm{~mm}$-cyanide in the late-exponential phase of growth was about $25 \%$ higher than that from organisms harvested earlier in growth (Fig. 3). This intensity of emission was not increased by the presence of salicylhydroxamic acid. The concentration of cyanide giving $50 \%$ stimulation of light emission from whole cells was around $0.7 \mathrm{~mm}$.

Dependence of chemiluminescence on the presence of $\mathrm{O}_{2}$ is shown in Fig. 4; switching from $\mathrm{O}_{2}$ to $\mathrm{N}_{2}$

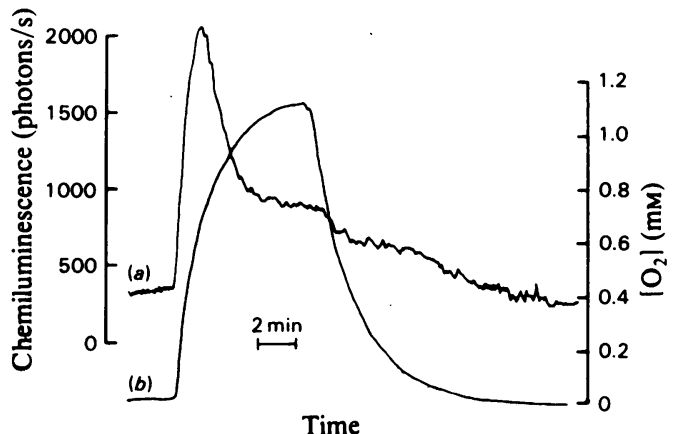

Fig. 5. Overshoot of luminescence during oxygenation of whole-cell suspension of $A$. castellanii in the presence of cyanide

Conditions were as described in Fig. 4. The concentration of cyanide was $2 \mathrm{~mm}$. (a) Chemiluminescence; (b), $\left[\mathrm{O}_{2}\right]$. gave a transition to anaerobiosis, which, as indicated by the polarographic trace, was complete in $6 \mathrm{~min}$. However, the accompanying decrease in lightintensity commenced immediately, whereas the dissolved oxygen concentration was still $>1.0 \mathrm{~mm}$. A return to $\mathrm{O}_{2}$ produced a rapid re-establishment of light intensity. When $2 \mathrm{~mm}$-cyanide was added to the oxygenated suspension, then $\mathrm{N}_{2}$ passed in, the decay of chemiluminescence was biphasic (Fig. 4). In the presence of cyanide the return to oxygenation from anaerobiosis produced an overshoot in photoemission (Fig. 5); this phenomenon was observed in both cyanide-stimulated and cyanide-inhibited cell types. The dependence of chemiluminescence on $\mathrm{O}_{2}$ concentration in the presence and absence of $2 \mathrm{~mm}$ cyanide for both cell types (Fig. 6) indicates the presence of two components, one with a high $\mathrm{O}_{2}$ concentration-dependence, and a second still functional at lower $\mathrm{O}_{2}$ partial pressures.

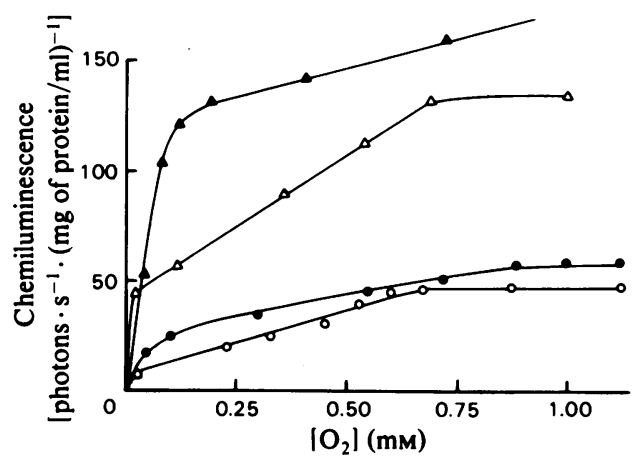

Fig. 6. Effect of oxygen concentration on chemiluminescence of $A$. castellanii

Early-exponential-phase organisms: $\triangle, 2$ mm-cyanide; $O$, without cyanide. Late-exponential-phase organisms: $\Delta, 2$ mm-cyanide; $\bullet$, without cyanide.

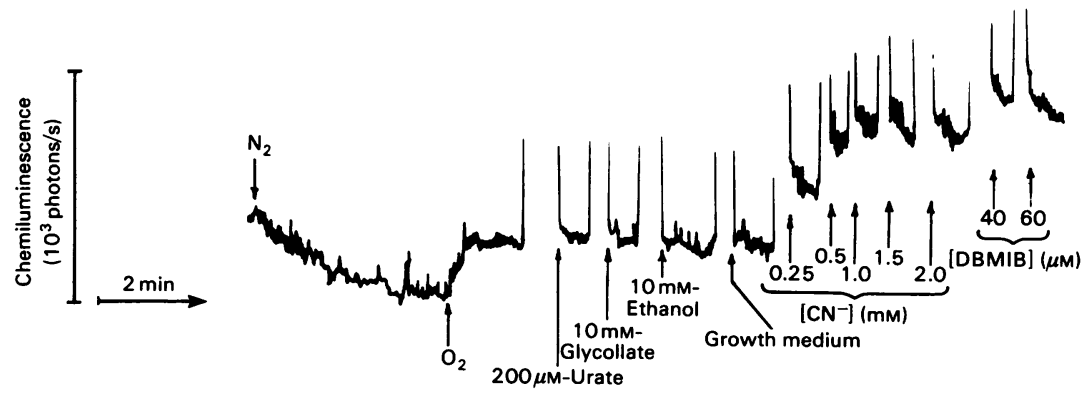

Fig. 7. Chemiluminescence of cell-free extract of $A$. castellanii

A cell-free extract (4.6 $\mathrm{mg}$ protein/ml) was prepared from organisms harvested in the late-exponential phase of growth $\left(2 \times 10^{6}\right.$ cells $\left./ \mathrm{ml}\right)$. Abbreviation used: DBMIB, dibromothymoquinone. 

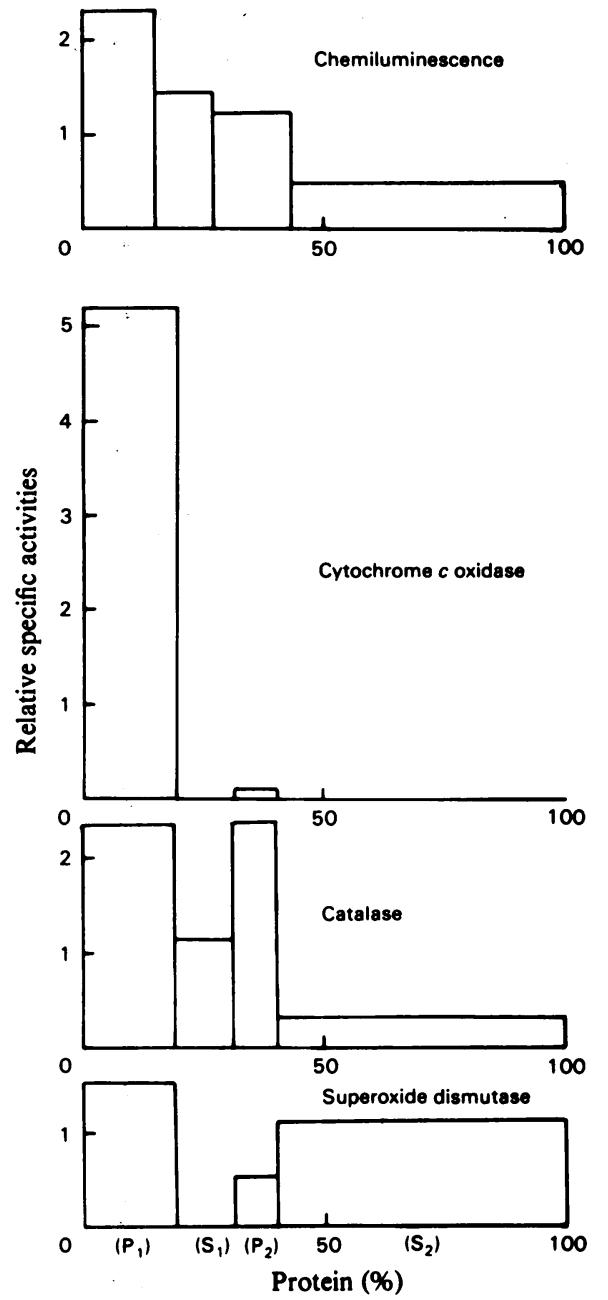

Fig. 8. Distribution of enzymes and photoemission (in the presence of $2 \mathrm{mM}$-cyanide) in cell-free extracts of $A$. castellanii after differential centrifugation

Relative specific activities (the ratios of specific activities in fractions to those in the cell-free extract) were plotted against cumulative percentage of protein recovered in each fraction. The centrifugal field increases from left to right. The far-right-hand bar represents the fraction containing particles nonsedimentable at $200000 \mathrm{~g}$-min. Percentage recoveries . (based on enzyme units in the cell-free extracts) were $99.4 \%$ for chemiluminescence, $90.1 \%$ for cytochrome $c$ oxidase, $78 \%$ for catalase, $130 \%$ for superoxide dismutase, and $118 \%$ for protein respectively. Chemiluminescence and enzyme distributions were determined in separate fractionations.

\section{Chemiluminescence of cell-free extracts and fractions}

Chemiluminescence of the cell-free extract (Fig. 7) showed some characteristics similar to those described previously for whole cells. Anaerobic-aerobic cycles of light-emission could be demonstrated, and the greatest responses were produced on adding cyanide and dibromothymoquinone. Addition of peroxisomal substrates (urate, glycollate or ethanol) gave no effect. Addition of growth medium (1.5\% glucose/ $0.75 \%$ yeast extract $/ 0.75 \%$ proteose-peptone) was also without effect.

Subcellular fractionation by differential centrifugation gave four fractions, $P_{1}, S_{1}, P_{2}$, and $S_{2}$ (Fig. 8). Distribution of light-emission (in the presence of $2 \mathrm{~mm}$-cyanide) among these fractions was compared with the distribution of cytochrome $c$ oxidase (mitochondrial marker enzyme), catalase (up to $98 \%$ peroxisomal; Morgan et al., 1973) and superoxide dismutase. Fraction $P_{1}$ contained $15 \%$ of the protein, $99 \%$ of the cytochrome $c$ oxidase, $45 \%$ of the catalase, $29 \%$ of the superoxide dismutase, and accounted for $35 \%$ of the total chemiluminescence. Fraction $S_{1}$ contained $12 \%$ of the protein, $14 \%$ of the catalase and gave $17 \%$ of the total photoemission. Fraction $P_{2}$ contained $16 \%$ of the protein, $21 \%$ of the catalase and gave $20 \%$ of the photoemission. Fraction $\mathrm{S}_{2}$ contained $57 \%$ of the protein, $20 \%$ of the catalase, $66 \%$ of the superoxide dismutase and accounted for $30 \%$ of the chemiluminescence.

No stimulation of photoemission was observed in any fraction by urate, glycollate, ethanol or growth medium, but all four fractions responded to addition of cyanide or cyanide-plus-dibromothymoquinone. Mitochondrial fractions from organisms harvested in early- or late-exponential phases of growth gave no increased photoemission over that observed under aerobic conditions on addition of succinate, NADH or 2-oxoglutarate in the presence or absence of ADP. Addition of t-butyl hydroperoxide gave a doubling of chemiluminescence intensity irrespective of previous additions. Chemiluminescence of cell-free extracts and subcellular fractions was slightly more sensitive to stimulation by cyanide than that of intact organisms (Fig. 9a); cyanide-dependencies for inhibition of cellular respiration, cytochrome $c$ oxidase, catalase and superoxide dismutase activities in a whole homogenate of $A$. castellanii are shown (Fig. 9b). Cellular respiration, cytochrome $c$ oxidase and catalase were all more sensitive to inhibition by cyanide ( $K_{\mathrm{i}}$ values 60,60 and $140 \mu \mathrm{M}$ respectively) than was stimulation of chemiluminescence by cyanide, but superoxide dismutase was half-inhibited at a concentration similar to that giving $50 \%$ of total cyanide-induced photoemission in cell-free extracts (0.3 mM).

\section{Discussion}

Acanthamoeba castellanii shows a 'low-level' chemiluminescence (as defined by Seliger, 1975) 


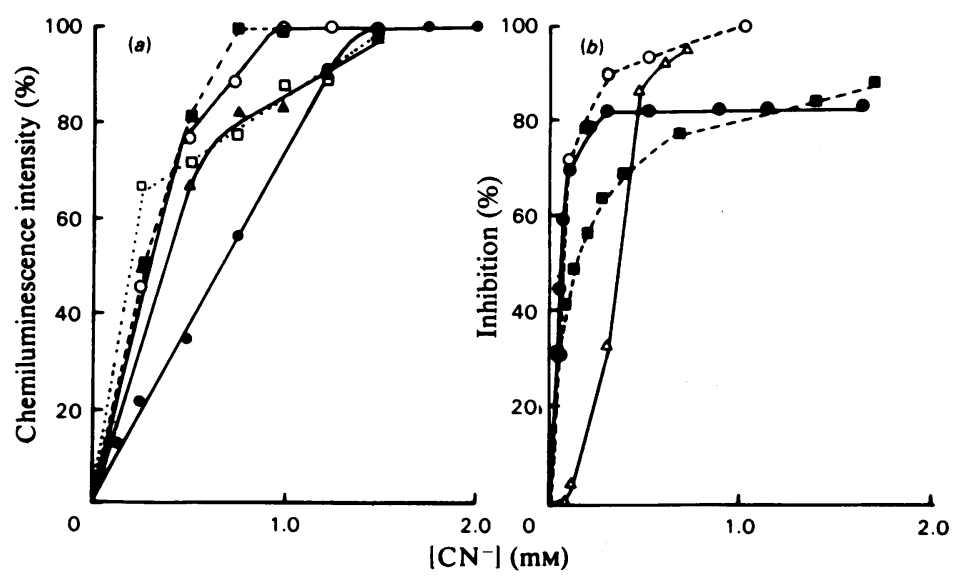

Fig. 9. Effect of cyanide on chemiluminescence of intact-cell suspensions, subcellular fractions and enzymes of A. castellanii (a) Cyanide stimulation of chemiluminescence (percentage of maximum intensity produced on cyanide addition) in: , intact late-exponential-phase cells resuspended at $2.7 \times 10^{7} / \mathrm{ml}$; $O$, whole homogenate $(4.6 \mathrm{mg} \mathrm{protein} / \mathrm{ml}) ; \square$, mitochondrial fraction $(1.8 \mathrm{mg}$ protein $/ \mathrm{ml}) ; \boldsymbol{\Delta}$, fraction sedimented at $200000 \mathrm{~g}-\mathrm{min}(110.5 \mathrm{mg}$ of protein $/ \mathrm{ml}) ; \Delta$, fraction non-sedimentable at $200000 \mathrm{~g}-\mathrm{min}(6.8 \mathrm{mg}$ of protein $/ \mathrm{ml})$. (b) Cyanide-sensitivity of: $\bullet$, respiration of: whole cells: $O$, cytochrome $c$ oxidase; $\square$, catalase; and $\Delta$, superoxide dismutase, in a whole homogenate of late-exponential-phase organisms $(0.2 \mathrm{mg}$ of protein $/ \mathrm{ml})$.

that is dependent on the presence of molecular oxygen, and its $\mathrm{O}_{2}$-concentration-dependence suggests the presence of two components. Its intensity is similar in organisms harvested early or late in exponential growth, even though the proportions of mitochondrial electron transport through the main phosphorylating chain and the two alternative oxidases differ markedly in the two cell types (Edwards \& Lloyd, 1978a,b). Thus the phenomenon of light-emission is not directly correlated with the extent of reduction of oxygen at respiratory sites other than cytochrome $c$ oxidase. Furthermore, cyanide specifically enhances photon emission in both cell types, whereas azide or antimycin $\mathrm{A}$ (both inhibitors of the main respiratory chain in $A$. castellanii) do not. In isolated mitochondria, succinate, 2-oxoglutarate or NADH additions made before cyanide do not increase the response of photon emission to this inhibitor.

Subcellular-fractionation experiments implicate a multiplicity of locations in photoemission; fractions containing mitochondria, peroxisomes and the microsomal fractions all exhibit cyanide-stimulated photoemission. Peroxisomal substrates (glycollate, urate and ethanol), which generate $\mathrm{H}_{2} \mathrm{O}_{2}$ in $A$. castellanii, did not produce increased chemiluminescence.

Enzymes sensitive to inhibition by cyanide in $A$. castellanii include cytochrome $c$ oxidase, catalase and superoxide dismutase. The concentrationdependence of stimulation of photoemission by cyanide resembles most closely the sensitivity of superoxide dismutase to this inhibitor; moreover, this enzyme activity is multilocational in subcellular fractions. It seems likely that the remarkable effect of cyanide on chemiluminescence is mediated via increased intracellular superoxide anion concentration, which may in turn increase the generation rate of hydroxy radicals (McCord \& Day, 1978; Halliwell, 1978), leading to lipid hydroperoxide and singlet-oxygen formation (Nakano et al., 1975; Sugioka \& Nakano, 1976). Singlet oxygen is itself chemiluminescent (Khan \& Kasha, 1963; Kearns, 1971).

The enhancement of $A$. castellanii chemiluminescence by t-butyl hydroperoxide, as previously observed in rat liver mitochondria and microsomal fractions (Boveris et al., 1979), seems to indicate that a lipid hydroperoxide $\left(\mathrm{RO}_{2} \mathrm{H}\right)$ and superoxide anions may afford the reactants that directly or indirectly lead to the formation of chemiluminescent species; recent evidence implicates haemoproteins in this process (E. Cadenas, personal communication).

Anaerobiosis in the presence of cyanide allows pools of intermediates to accumulate that give a burst of chemiluminescence on admission of $\mathrm{O}_{2}$. Possible candidates include ubisemiquinone (Boveris et al., 1976; Cadenas et al., 1977) and a reduced form of an autoxidizable cytochrome $b$ (Loschen et al., 1973). The action of dibromothymoquinone requires further investigation, but it is noteworthy that this inhibitor enhances chemiluminescence only when cyanide is present. That this quinone analogue produces an effect in all subcellular fractions means that its action is not restricted to a site at the ubiquinone-cytochrome $b$ areas of the respiratory chain 
(Trebst et al., 1970). It seems likely that dibromothymoquinone, similarly to other benzo- and naphtho-quinones (Boveris et al., 1976, 1978), could be reduced by different intracellular redox systems and then originate superoxide anion by autoxidation.

Chemiluminescence seems to afford an integrative measurement of reactions closely related to lipid and organic peroxide formation. It offers unique advantages as a non-destructive assay with high sensitivity, since light-emission enables the detection of $100 \mathrm{am}-$ $10 \mathrm{fm}$ concentrations of the photoemissive species.

This work was supported by grant no. HL-SCOR-15061 from the U.S. Public Health Service. We thank Dr. W. D. Bonner for the facilities for growth of the organism. D. L. held a Leverhulme Fellowship, and thanks Miss. J. Ball for technical assistance. A. B. held a J.S. Guggenheim Memorial Fellowship and is Career Investigator from the Consejo Nacional de Investigaciones Cientificas y Téchicas (Argentina).

\section{References}

Boveris, A. \& Cadenas, E. (1975) FEBS Lett. 54, 311-314 Boveris, A. \& Stoppani, A. O. M. (1977) Experientia 33, 1306-1308

Boveris, A., Oshino, N. \& Chance, B. (1972) Biochem. J. 128, 617-630

Boveris, A., Cadenas, E. \& Stoppani, A. O. M. (1976) Biochem. J. 156, 435-444

Boveris, A., Docampo, R., Turrens, J. F. \& Stoppani, A. O. M. (1978) Biochem. J. 175, 431-439

Boveris, A., Chance, B., Filipkowski, M., Nakase, Y. \& Paul, K. G. (1979) in Frontiers of Biological Energetics (Scarpa, A., Dutton, P. L. \& Leigh, J.S., eds.), vol. 2, pp. 975-984 Academic Press, New York

Cadenas, E., Boveris, A., Ragan, C. I. \& Stoppani, A. O. M. (1977) Arch. Biochem. Biophys. 180, 248-257

Chance, B. \& Boveris, A. (1978) in Extrapulmonary Manifestations of Respiratory Disease (Robin, E., ed.), pp. 185-237, M. Dekker, New York

Edwards, S. W. \& Lloyd, D. (1977) J. Gen. Microbiol. 103, 207-213

Edwards, S. W. \& Lloyd, D. (1978a) Biochem. J. 174, 203-211

Edwards, S. W. \& Lloyd, D. (1978b) in Function of Alternative Terminal Oxidases (Degn, H., Lloyd, D. \& Hill, G. C., eds.), pp. 31-37, Pergamon Press, Oxford
Edwards, S. W., Chagla, A. H., Griffiths, A. J. \& Lloyd, D. (1977) Biochem. J. 168, 113-121

Esser, A. \& Stauff, J. (1968) Z. Naturforsch. 23B, 1554 1555

Halliwell, B. (1978) FEBS Lett. 92, 312-326

Howes, R. M. \& Steele, R. H. (1971) Res. Commun. Chem. Pathol. Pharmacol. 2, 619-626

Howes, R. M. \& Steele, R. H. (1972) Res. Commun. Chem. Pathol. Pharmacol. 3, 349-357

Kearns, D. R. (1971) Chem. Rev. 71, 395-427

Khan, A. U. \& Kasha, M. (1963) J. Chem. Phys. 39, 2105-2106

Lloyd, D., Edwards, S. W., Kristensen, B. \& Degn, H. (1979) Biochem. J. 182, 11-15

Loschen, G., Flohe, L. \& Chance, B. (1971) FEBS Lett. 18, 261-264

Loschen, G., Azzi, A. \& Flohe, L. (1973) FEBS Lett. 33, 84-88

Loschen, G., Azzi, A., Richter, C. \& Flohe, L. (1974) FEBS Lett. 42, 68-72

Lowry, O. H., Rosebrough, N. J., Farr, A. L. \& Randall, R. J. (1951) J. Biol. Chem. 193, 265-275

Lück, H. (1963) in Methods of Enzymatic Analysis (Bergmeyer, H. U., ed.), p. 885, Academic Press, New York

McCord, J. M. \& Day, E. D. (1978) FEBS Lett. 86, 139142

Morgan, N. A., Howells, L., Cartledge, T. G. \& Lloyd, D. (1973) in Methodological Developments in Biochemistry (Reid, E., ed.), vol. 3, pp. 219-232, Longman, London

Nakano, M., Noguchi, T., Sugioka, K., Fukuyama, H., Sato, M., Shimizu, Y., Tsuji, Y. \& Inaba, H. (1975) J. Biol. Chem. 250, 2404-2406

Pyatenko, V. S. \& Tarusov, V. N. (1964) Biofizika 9, 134-135

Quickenden, T. I. \& QueHee, S. S. (1974) Biochem. Biophys. Res. Commun. 60, 764-770

Rich, P. R. \& Bonner, W. D., Jr. (1978) Arch. Biochem. Biophys. 188, 206-213

Seliger, H. H. (1975) Photochem. Photobiol. 4, 1189-1205

Stauff, J. \& Reske, G. (1964) Naturwissenschaften 51, 39-40

Smith, L. (1955) Methods Enzymol. 2, 732-740

Sugioka, K. \& Nakano, M. (1976) Biochim. Biophys. Acta 423, 203-216

Tarusov, B. N., Polivoda, A. I. \& Zhuravlev, A. I. (1961) Radiobiologiya 1, 150-151

Tarusov, B. N., Polivoda, A. I., Zhuravlev, A. I. \& Sekamova, E. N. (1962) Tsitologiya 4, 696-699

Trebst, A., Horth, H. \& Draber, W. (1970) Z. Naturforsch. 25B, 1157-1159 